Dicle University Journal of Engineering (DUJE)

\title{
Mardin ilinin hayvansal atık kaynaklı biyogaz potansiyelinin belirlenmesi
}

\section{Determination of biogas potential from animal waste in Mardin province}

\author{
İbrahim YENIGÜN ${ }^{1}$, Hakkı GÜLŞEN ${ }^{2}$, Abdullah YENIGÜ̈ ${ }^{3 *}$ \\ ${ }^{1}$ HarranÜniversitesi, Güzel Sanatlar Fakültesi, Mimarlk Bölümü, Șanluurfa, ibrahimyenigun@ @arran.edu.tr, ORCiD ID: 0000-0003-4742-0160 \\ ${ }^{2}$ Harran Üniversitesi, Mühendislik Fakültesi, Çevre Mühendisliği Bölümü, Şanluurfa, hgulsen@ harran.edu.tr, ORCID İD: 0000-0002-0726-555X \\ ${ }^{3 *}$ Harran Üniversitesi, Fen Bilimleri Enstitüsü, Şanliurfa, abdullah.yenigun@mardin.bel.tr, ORCID ID: 0000-0001-9117-2171
}

\begin{tabular}{|c|c|}
\hline \multicolumn{2}{|c|}{ MAKALE BİLGİLERİ } \\
\hline \multicolumn{2}{|c|}{ Makale geçmişi: } \\
\hline Geliş: & 28 Ocak 2021 \\
\hline Düzeltme: & 10 Mayıs 2021 \\
\hline Kabul: & 20 Mayıs 2021 \\
\hline
\end{tabular}

Doi: $10.24012 /$ dumf. 955496

\begin{abstract}
ÖZET
Dünyada nüfus artışına bağlı olarak, her geçen gün enerjiye olan gereksinim artış göstermektedir. Özellikle Türkiye gibi gelişen ülkelerde sanayinin gelişmesi, gelir seviyesinin artması ve teknoloji ile birlikte geliştirilen yeni nesil ürünlere paralel olarak ileriki senelerde enerji ihtiyacının daha da artacağı düşünülmektedir. Bununla birlikte günümüzde kullanılan fosil kaynakların dünyada çok önemli çevresel sorunlar oluşturması ve bu kaynakların çok yakın bir gelecekte bitecek olması gibi faktörler çevre dostu enerji kaynaklarına olan yönelime ivme kazandırmıştır. Bu düşüncelerden hareketle çalışmada; yenilenebilir enerji ürünlerinden biri olan biyogaz için Mardin ili hayvansal atık potansiyelinin belirlenmesi amaçlanmıştır. Bu amaca bağlı olarak çalışmada, İl Tarım ve Orman Müdürlüğ̈̈’nün güncel verileri kullanılarak küçükbaș, büyükbaș ve kanatlı hayvan varlığına göre oluşacak gübre miktarları hesap edilmiş, muhtemel yıllık biyogaz miktarı hesaplanmıştır. Çıkan sonuçla ise üretilebilecek enerji potansiyeli ortaya konmuştur. Buna göre; Mardin il sınırları içerisindeki hayvanlardan temin edilebilecek gübrenin çürütülmesi ile yıllık $177823801 \mathrm{~m} 3$ biyogaz ve bu biyogazdan yaklaşık 404600 GJ enerji üretim potansiyeli olduğu ve elektrik enerjisi eşdeğeri ise günde $229512 \mathrm{kWh}$ olabileceği belirlenmiştir.
\end{abstract}

\begin{tabular}{|c|c|}
\hline ARTICLE INFO & ABSTRACT \\
\hline Article history: & \multirow{6}{*}{$\begin{array}{l}\text { Depending on the population growth in the world, the need for energy is increasing day by day. In particular, the } \\
\text { development of industry in developing countries such as Turkey, which was developed together with the increase } \\
\text { of income levels and technology are considered in parallel with the new generation of products will further } \\
\text { increase the demand for energy in the yearahead. However, factors such as the fossil resources used today, which } \\
\text { create very important environmental problems in the world and that these resources will end in the very near } \\
\text { future have accelerated the trend towards environmentally friendly energy resources. Working with these } \\
\text { thoughts; It is aimed to determine the animal waste potential of the province of Mardin for biogas, one of the } \\
\text { renewable energy products. Depending on this purpose, the amount of fertilizer to be formed according to the } \\
\text { presence of ovine, bovine and poultry was calculated using the current data of the Provincial Directorate of } \\
\text { Agriculture and Forestry, and the possible annual biogas amount was calculated. As a result, the energy potential } \\
\text { that can be produced has been revealed. According to this; With the digestion of the manure that can be obtained } \\
\text { from the animals within the borders of Mardin province, it has been determined that there is an annual biogas } \\
\text { potential of } 17794331 \mathrm{~m} 3 \text { and an energy production potential of } 403931 \text { GJ from this biogas and the equivalent } \\
\text { of electrical energy can be } 229131 \mathrm{kWh} \text { per day. }\end{array}$} \\
\hline 28 January 2021 & \\
\hline 10 May 2021 & \\
\hline Accepted: 20 May 2021 & \\
\hline Keywords: & \\
\hline Animal waste, Biogas, Mardin & \\
\hline
\end{tabular}




\section{Giriş}

Nüfus artışı ile birlikte, insanların enerji talebinde de sürekli bir artış olmaktadır [1]. Dünyada son yıllarda 17 kat artan enerji tüketimi, fosil yakıtların sebep olduğu ve ortama atılan kükürtdioksit, azotoksitler ve karbondioksit gibi çevreye zararlı gazları da arttırmıştır [2]. Fosil yakıtların işlenmesinden elde edilen enerjinin çevreye verdiği zarar tüm çevrelerce bilinmektedir. $\mathrm{Bu}$ nedenle hangi enerji kaynağ1 kullanılacaksa çevreye olan etkisiyle beraber değerlendirilmektedir [3]. Mevcut fosil yakıtların; yakın gelecekte tükenecek olması, ciddi çevre sorunlarına yol açması, fosil yakıt üreten ülkelere bağımlılığın çeşitli ekonomik ve siyasi sorunlara sebep olmasi ve fiyat istikrasızlığı nedeni ile insanları yeni enerji kaynakları bulmaya zorlamıştır. Bunun sonucunda hidrolik, jeotermal, güneş, rüzgâr, biyokütle, dalga, hidrojen vb. olan yenilenebilir enerji kaynakları üzerinde çalışmalar yoğunlaşmıştır [4].

Yenilenebilir enerji kaynakları içinde bitkisel, hayvansal ve organik içerikli şehir ve endüstriyel atıklardan oluşan biyokütle önemli bir yer tutmaktadır [5]. Biyokütlenin uzak bölgelerde özelikle enerjiden yoksun yerlerde üretilmesi ile bu bölgelerin gelişimine katkı sağlanması ve istihdamın arttırılması mümkündür [6].

Biyokütlenin oksijen olmayan ortamda fermente edilmesi sonucunda; meydana çıkan renksiz, kokusu olmayan, havadan çok daha hafif, parlak açık mavi alev ile yanan ve içeriğinde yaklaşık; $\%$ 40-70 $\mathrm{CH}_{4}, \%$ 30-60 $\mathrm{CO}_{2}, \%$ 0-3 $\mathrm{H}_{2} \mathrm{~S}$ ile az miktarda $\mathrm{N}$ ve $\mathrm{H}$ bulunan biyogaz oluşmaktadır [3-7]. Biyogazın; oluştuğu gazlardan $\mathrm{CH}_{4}$ oranına göre 1sıl değeri bir $\mathrm{m}^{3}$ 'te $17-25 \mathrm{MJ}$ aralığında değişir [8].

Dünyada biyogaz üretiminde en fazla büyük baş hayvanların gübreleri kullanılmaktadır. Bunun en önemli nedeni günlük gübre miktarları diğer hayvanlarınkine göre daha fazla olmasıdır. Süt sığırlarının atıklarındaki katı madde miktarı et sığırlarınınkine oranla daha düşüktür. Süt sığırlarının gübre içeriğindeki lifler yüksek düzeyde çürümeye dirençli olduğu ve su ile lif içerikleri yüksek olmasından dolayı daha düşük oranda metan gazı elde edilir [9].

Öteki hayvan gübrelerine oranlanırsa, kümes hayvanların gübresi daha fazla biyolojik olarak parçalanabilen organik madde içermektedir. Yaş gübre oluşumu bir tavuk başına 0,08-0,125 $\mathrm{kg} /$ gün aralığında olup bunun da ortalama \%2025 miktarı kadar katı madde ihtiva eder. Bunun da \%55-65 aralığı kadarı uçucu katı maddedir. $\mathrm{Bu}$ da, bu tür hayvanların gübresinin önemli bir biyogaz kaynağı olduğunu göstermektedir [6].

Noorollahi ve arkadaşları [10], İran'daki farklı iller için besi hayvanlarının gübresinden, inek sayıs1, üretilen gübre miktarı ve bir kilogram hayvan atığı başına oluşturulan biyogaz hacmi ile ilgili istatistiksel veriler kullanılarak elde edilebilecek biyogaz potansiyelini hesaplamışlardır. Çalışma sonucunda çiftlik hayvanı atıklarından biyogaz üretiminin potansiyel olarak ülkenin doğal gaz talebinin bir kısmını karşılayabileceğini gösterdi. İran'ın Sistan-Baluchestan ve Ilam bölgelerinin yüksek gaz tüketimi ve devasa biyogaz üretim potansiyelinden dolayı öncelikli biyogaz üretim bölgeleri olması gerektiği kanaatine varmışlardır.

Benzer şekilde, Abdeshahian ve arkadaşları [11], muazzam bir biyogaz kaynağı sağlayan gübre, kan ve işkembe içeriği de dahil olmak üzere büyük miktarda hayvan atı̆gı üretilen Malezya bölgesinde bulunan çiftliklerdeki hayvanların gübrelerinden elde edilebilecek biyogaz potansiyeli üzerine yapmış oldukları çalışmada, Malezya çiftliklerindeki hayvan gübrelerinden yıllık 4589,49 milyon-m3/yıl biyogaz üretilebileceğini hesaplamışlardır.

Tüm bu veriler değerlendirildiğinde; dünyanın değişik ülkelerinde hesaplandığı gibi Ülkemizde de biyogaz üretim potansiyelinin araştırılması ve neticesinde oluşacak enerji miktarının belirlenmesi ekonomik sürdürülebilirlik ve çevre 
politikaları açısından önemi açıkça görülmektedir.

illerindeki biyogaz potansiyelini belirlemek için yapılan çalışmalardaki hayvansal atıklar ile ilgili yapılan kabuller kullanılmıştır

$\mathrm{Bu}$ çalışmada Mardin İli için biyogaz üretim potansiyeli ve bundan elde edilebilecek enerji miktarı incelenmiştir. Bu kapsamda Mardin bölgesinde mevcut olan kanatl1, küçükbaş ve büyükbaş hayvan miktarı tespit edilmiş ve bu hayvanların bir günde ürettikleri gübreler dikkate alınarak günlük ve yıllık atık miktarlarının hesabı yapılmıştır. Daha sonra her hayvanın gübresindeki biyogaz elde edilebilecek potansiyele göre üretilebilecek biyogaz miktarı ve buna bağli enerji potansiyeli hesaplanmıştır.

\section{Materyal ve Yöntem}

$\mathrm{Bu}$ çalışmada, Mardin İl Tarım ve Orman Müdürlüğünün 2020 yılı verileri kullanılarak, İldeki mevcut kümes, küçükbaş ve büyükbaş hayvan varlığından elde edilen atık miktarları ve biyogaz potansiyelinin hesabı yapılmıştır.

Mardin ilindeki hayvansal atıkların biyogaz potansiyelini belirlemek için Burdur ve [12-13]. Hayvansal atıklar ile ilgili kabuller; küçükbaş hayvandan yılda 0,7 ton yaş gübre edilirken, büyükbaş hayvandan yılda 3,6 ton yaş gübre elde edildiği ve bir kanatlı hayvandan ise y1lda 0,022 ton yaş gübre elde edildiği kabul edilmiştir [12-13]. Elde edilebilen; kümes hayvanları gübrelerinin $\% \quad 99$, küçükbaş gübrelerinin $\% \quad 13$ ve büyükbaş hayvan gübrelerinin \% 65 olduğu geri kalan kısmın meralarda kaybolduğu kabul edilmiştir [12-13]. Ayrıca bir ton yaş kanatlı gübresinden yılda 78 $\mathrm{m}^{3}$ biyogaz, bir ton yaş sığır gübresinden yılda 33 $\mathrm{m}^{3}$ biyogaz ve1 ton koyun gübresinden ise y1lda $58 \mathrm{~m}^{3}$ biyogaz elde edileceği kabul edilmiştir [12-13]. Hayvansal atıkların 1sıl değeri 22,7 $\mathrm{MJ} / \mathrm{m}^{3}$ olarak [13] ve $1 \mathrm{~m}^{3}$ biyogaz $4,70 \mathrm{kWh}$ enerji olarak alınmıştır [5].

Mardin ili 2020 y1lı İl Tarım ve Orman Müdürlüğü verilerine göre, hayvan sayılarının ilçelere göre dağılımı Tablo 1'de verilmiştir.

Tablo 1. Mardin ili 2020 yılı hayvan sayıları

\begin{tabular}{lrrrr}
\hline İLÇE & BÜYÜKBAŞ & KÜÇÜKBAŞ & KANATLI & TOPLAM \\
\hline Artuklu & 5753 & 114464 & 495350 & \\
Midyat & 17424 & 71648 & 568214 & \\
Kizıltepe & 9750 & 96031 & 267000 & \\
Nusaybin & 9096 & 122527 & & \\
Mazidağ1 & 8140 & 160722 & & \\
Derik & 48637 & 330654 & & \\
Savur & 7885 & 97296 & & \\
Ömerli & 2359 & 21514 & & \\
Dargeçit & 8147 & 42048 & & \\
Yeşilli & 1134 & 47070 & 352920 & \\
TOPLAM & $\mathbf{1 1 8 ~ 3 2 5}$ & $\mathbf{1 1 0 3 9 7 4}$ & $\mathbf{1 6 8 3 ~ 4 8 4}$ & $\mathbf{2 9 0 5 ~ 7 8 3}$ \\
\hline
\end{tabular}




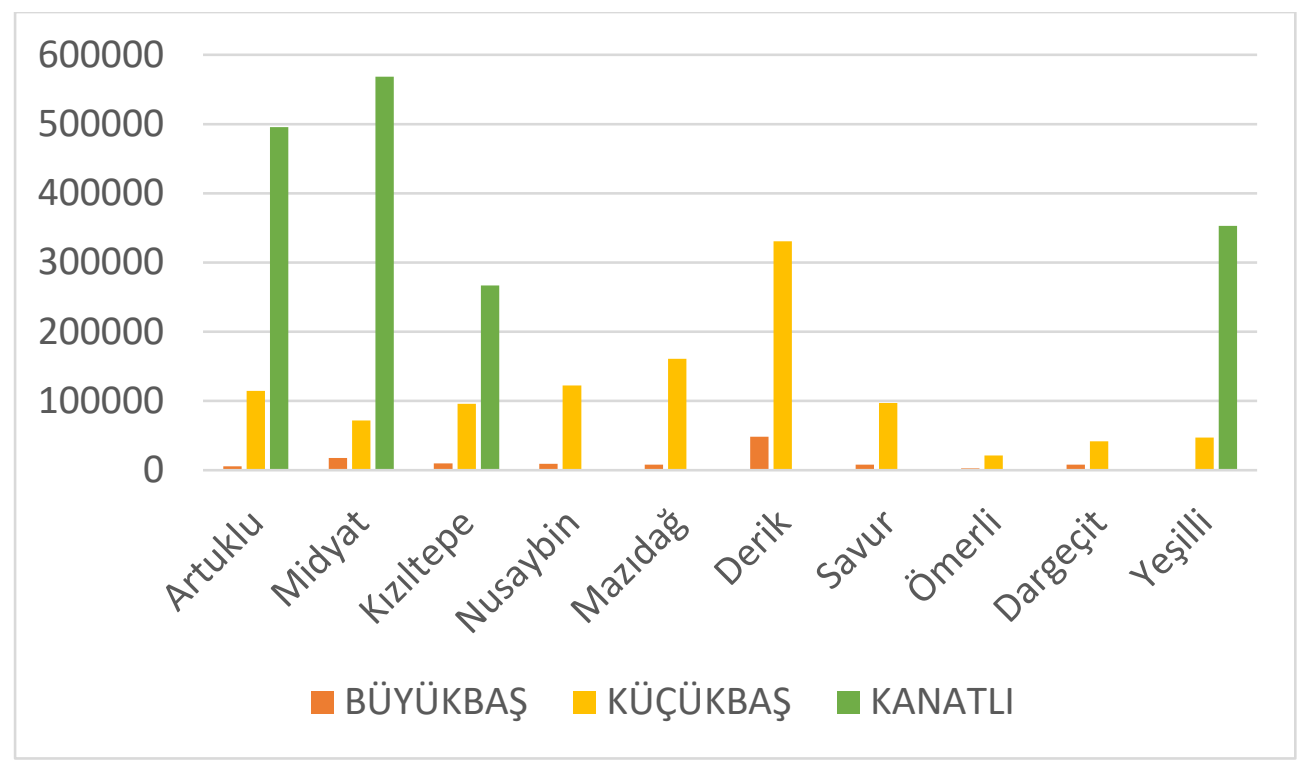

Şekil 1. Il genelindeki toplam hayvan sayılarının ilçe bazında dă̆ılımı

\section{Bulgular ve Tartışma}

Kanatlı hayvancılığın yüksek sayıda yetiştirildiği Mardin'de yüksek oranda yumurta tavukçuluğu yapılmaktadır. Bunun yanında küçükbaş hayvancılı̆̆ 1 da önemli bir yer tutmaktadır. Büyük ölçüde mera hayvancılığı yapılan küçükbaş türleri olarak; koyun ve keçi beslenmektedir. Diğer taraftan büyükbaş besi hayvancılığı da gittikçe artış göstermektedir. İlin hayvan varlığı, ilçelere göre Tablo.1'de gösterilmiştir.

Tablo.1 verilerine göre Mardin İli genelinde toplamda 2905783 adet hayvan yaşadığ görülmektedir. Şekil.1'e göre Artuklu, Midyat, Kızıltepe ve Yeşilli'de kanatlı hayvanların yoğun olduğu, Küçükbaş hayvanların da dağlık kesimden oluşan Derik, Mazıdağ ve Artuklu ilçelerinde yoğunlaştı̆̆ 1 görülmektedir. Büyükbaş olarak da en fazla Derik ilçesinde bulunmaktadır.

Araştırmada, hayvan sayılarına göre elde edilebilir atık miktarı hesaplanmış ve Tablo.2'de gösterilmiştir. Bu tabloya göre; Mardin İlindeki atık miktarı yıllık 414008 tondur. Şekil 2'ye göre, bu atığın büyük çoğunluğu (yaklaşık 4/6'sı) büyükbaş hayvan gübresinden elde edilmektedir. İlçeler bazında da yarısından fazlası Derik'ten sağlanmaktadır. Diğer ilçelerde ise durum, yakın miktarlarla birbirini takip etmektedir. 
Tablo 2. Hayvan sayısına göre elde edilebilir atık miktarları

\begin{tabular}{|c|c|c|c|c|}
\hline İLÇE & $\begin{array}{r}\text { BÜYÜKBAŞ } \\
\text { Atık Miktarı } \\
\text { (ton/y1l) }\end{array}$ & $\begin{array}{r}\text { KÜÇÜKBAŞ } \\
\text { Atık Miktar1 } \\
\text { (ton/y1l) }\end{array}$ & $\begin{array}{r}\text { KANATLI } \\
\text { Atık Miktarı } \\
(\text { ton/y1l) }\end{array}$ & $\begin{array}{r}\text { TOPLAM } \\
\text { Atık Miktar1 } \\
(\text { ton/y1l) }\end{array}$ \\
\hline Artuklu & 13462 & 10416 & 10789 & 34667 \\
\hline Midyat & 40772 & 6520 & 12376 & 59668 \\
\hline K1z1ltepe & 22815 & 8739 & 5815 & 37369 \\
\hline Nusaybin & 21285 & 11150 & & 32435 \\
\hline Mazıdağ & 19048 & 14626 & & 33673 \\
\hline Derik & 113811 & 30090 & & 143900 \\
\hline Savur & 18451 & 8854 & & 27305 \\
\hline Ömerli & 5520 & 1958 & & 7478 \\
\hline Dargeçit & 19064 & 3826 & & 22890 \\
\hline Yeşilli & 2654 & 4283 & 7687 & 14624 \\
\hline TOPLAM & 276881 & 100462 & 36666 & 414008 \\
\hline
\end{tabular}

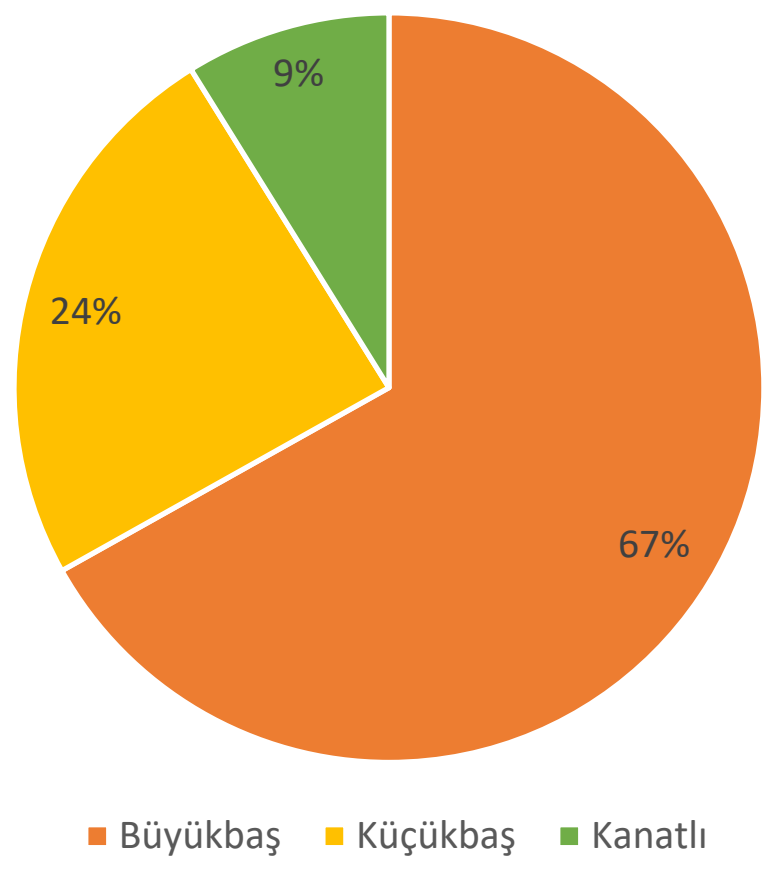

Şekil 2. Hayvan türüne göre atık miktarı

Kullanılabilir atık miktarından hesaplanan İ genelinde üretilebilecek biyogaz potansiyeli Tablo.3'te verilmiştir. Verilere göre y1llık üretilebilecek biyogaz miktarı 177823801 $\mathrm{m}^{3}$ 'tür. $\mathrm{Bu}$ değerin yaklaşık yarısı büyükbaş hayvan atığından elde edilmektedir. Geri kalan \%33'ü küçükbaş ve \%16's1 da kanatlı hayvanlardan sağlanmaktadır. Bu durum Şekil 4'te gösterilmiştir. Şekil 3'te ilçe bazında en büyük biyogaz potansiyelinin Derik ilçesi olduğu görülmektedir. 
Tablo 3. Hayvanların yılda ürettikleri gübre miktarlarına göre biyogaz üretimi

\begin{tabular}{|c|c|c|c|c|}
\hline İLÇE & $\begin{array}{r}\text { BÜYÜKBAŞ } \\
\text { Biyogaz } \\
\text { Miktar1 } \\
\left(\mathrm{m}^{3} / \mathrm{y} 1 \mathrm{l}\right)\end{array}$ & $\begin{array}{r}\text { KÜÇÜKBAŞ } \\
\text { Biyogaz } \\
\text { Miktarı } \\
\left(\mathrm{m}^{3} / \mathrm{y} 1 \mathrm{l}\right)\end{array}$ & $\begin{array}{r}\text { KANATLI } \\
\text { Biyogaz } \\
\text { Miktar1 } \\
\left(\mathrm{m}^{3} / \mathrm{y} 1 \mathrm{l}\right)\end{array}$ & $\begin{array}{r}\text { TOPLAM } \\
\text { Biyogaz } \\
\text { Miktar1 } \\
\left(\mathrm{m}^{3} / \mathrm{y} 1 \mathrm{l}\right)\end{array}$ \\
\hline Artuklu & 444247 & 604141 & 841520 & 1889908 \\
\hline Midyat & 1345481 & 378158 & 965305 & 2688944 \\
\hline Kiz1ltepe & 752895 & 506852 & 453590 & 1713337 \\
\hline Nusaybin & 702393 & 646698 & & 1349091 \\
\hline Mazıdağ & 628571 & 848391 & & 1476862 \\
\hline Derik & 3755749 & 1745192 & & 5500941 \\
\hline Savur & 608880 & 513528 & & 1122408 \\
\hline Ömerli & 182162 & 113551 & & 295713 \\
\hline Dargeçit & 629111 & 221929 & & 851041 \\
\hline Yeșilli & 87567 & 248435 & 599555 & 935558 \\
\hline TOPLAM & 9137057 & 5826775 & 2859970 & 17823801 \\
\hline
\end{tabular}

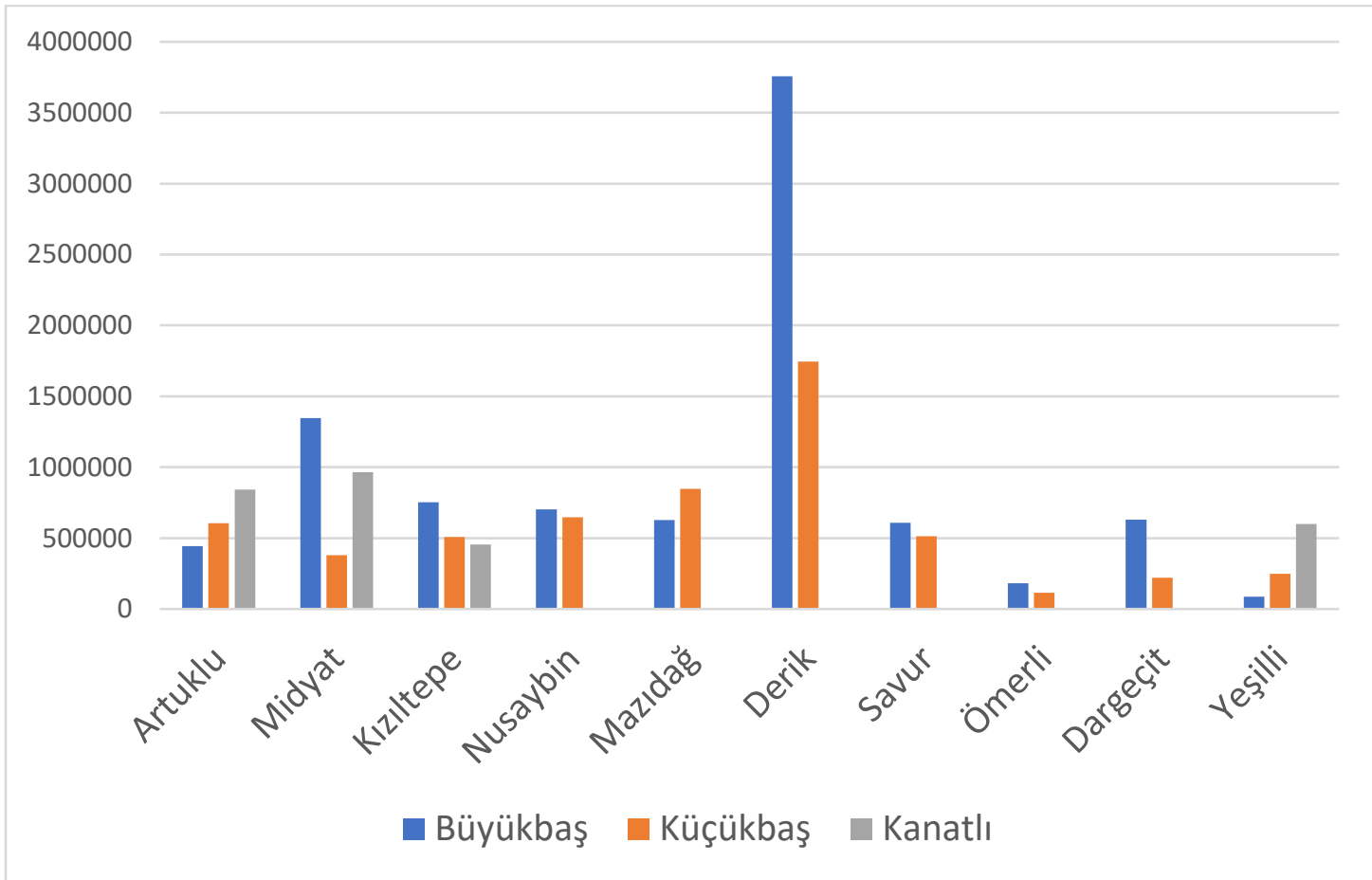

Şekil 3. Illçeler bazında ve hayvan türüne göre biyogaz üretim potansiyeli 


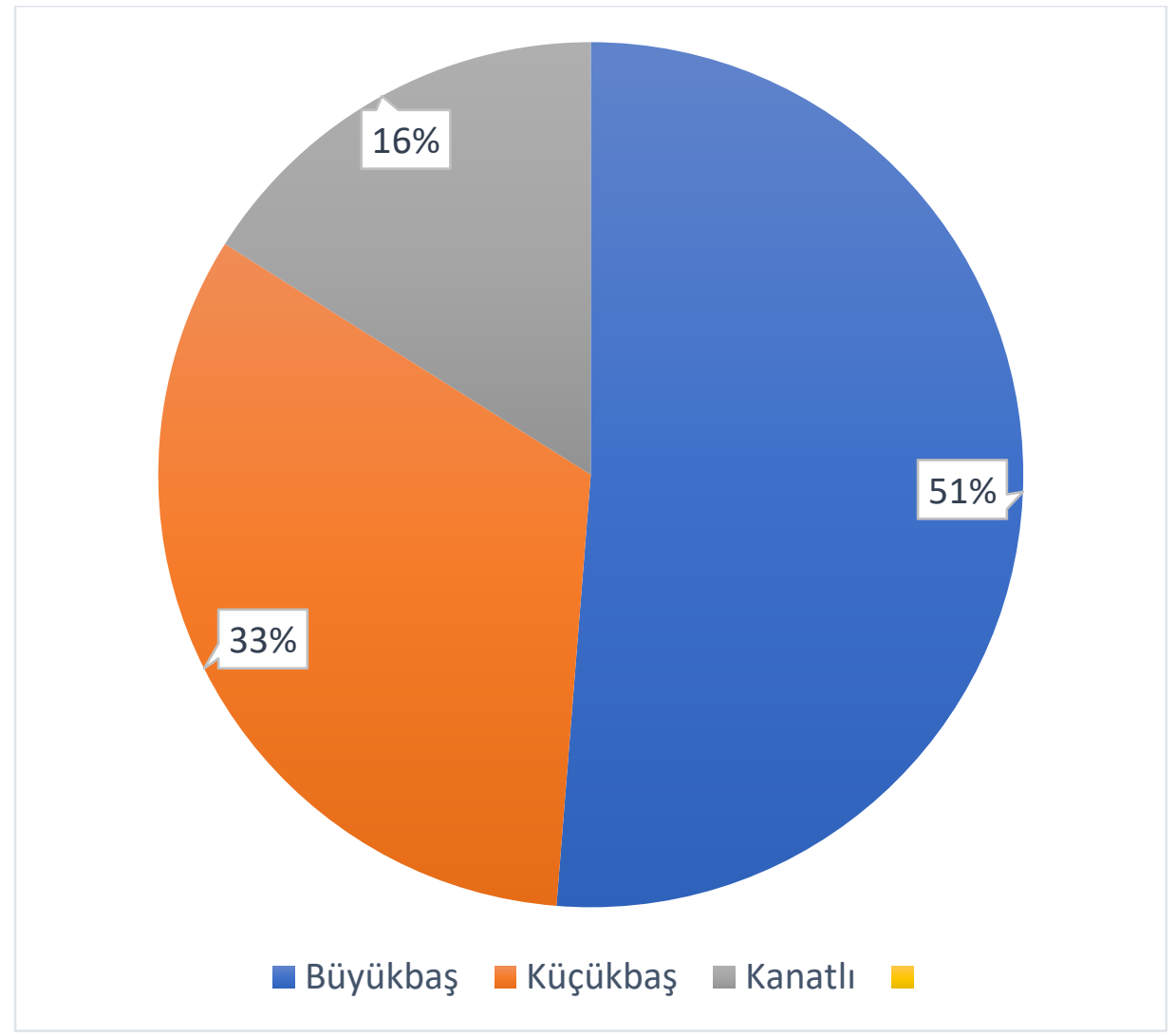

Şekil 4. Hayvan atıklarından elde edilebilir biyogaz potansiyeli

İlin biyogaz enerji potansiyelinin enerji y1llı 404600 GJ ve günde 229512 kWh elektrik kaynaklarındaki karşılığı Tablo 4'te verilmiştir. enerjisine eşit olduğu görülmektedir.

Tablo incelendiğinde; biyogaz potansiyelinin

Tablo 4. Toplam ylllı elde edilebilir enerji potansiyeli ve günlük elektrik enerjisi eşdeğeri

\begin{tabular}{lrr}
\hline Hayvan Türü & $\begin{array}{r}\text { Elde Edilebilir Enerji } \\
\text { Potansiyeli (GJ/yl) }\end{array}$ & $\begin{array}{r}\text { Elektrik Enerjisi } \\
\text { Eşdeğeri (kWh/gün) }\end{array}$ \\
\hline Büyükbaş & 207411 & 117655 \\
Küçükbaş & 132268 & 75030 \\
Kanatlı & 64921 & 36826 \\
TOPLAM & $\mathbf{4 0 4} \mathbf{6 0 0}$ & $\mathbf{2 2 9} \mathbf{5 1 2}$ \\
\hline
\end{tabular}

\section{Sonuç}

Ülkemiz, iklimsel özellikleri nedeniyle tarım ve hayvancilik konusunda önemli bir potansiyele sahiptir. Aynı zamanda gelişmekte olan ülkeler arasında bulunmasindan dolayı enerji ihtiyacı sürekli artmaktadır. Yerli enerji kaynaklarının araştırılması enerji güvenliği için önem arz etmektedir. Yerli ve yenilenebilir enerji kaynaklarından olan biyokütle enerjisinin ülkemiz için önemli bir kaynak olduğu görülmektedir. Biyokütleden de biyogaz elde edimesi yaygin olarak kullanılan bir yöntemdir. 
Özellikle atıksu arıtma çamurları, hayvansal ve bitkisel atıklar önemli bir biyogaz potansiyeli oluşturmaktadır.

Mardin ilinin iki ülkenin sınır şehri olması, hayvancılık, tarım ürünlerinin yoğun şekilde üretildiği ve iklim koşullarının uygun olduğu değerlendirildiğinde üretilecek biyogazın bölgeye katkı sağlayacağı aşikârdır. $\mathrm{Bu}$ kapsamda bu çalışmada ilimizin hayvan sayısı kapasitesine göre biyogaz potansiyeli ve enerji eşdeğeri hesaplanmıştır.

Araştırmada hayvan sayısından yola çıkıldığında Mardin İlindeki biyogaz potansiyeli ve enerji eşdeğeri bulunmuştur. Buna göre ilin hayvan sayısına göre elde edilebilir yıllık $177823801 \mathrm{~m}^{3}$ biyogaz potansiyeli olduğu görülmektedir. Bunun da elde edilebilir enerji potansiyeli yıllık 404600 GJ ve elektrik enerjisi eşdeğeri günde 229512 kWh'tır. İlçeler bazında da en yüksek elde edilebilir biyogaz potansiyeli Derik'te görünmektedir.

Sonuç olarak; Mardin ilinde kurulacak biyogaz tesisinin hem ekonomik hem de enerji güvenliği açısından başta bölge olmak üzere Türkiye'ye önemli katkılar getireceği nettir. Kurulacak tesisin, Artuklu-Derik-Kizıltepe ilçeleri arasında kurulmasının ise pek çok konuda uygunluk gösterdiği söylenebilir.

\section{Kaynaklar}

[1] As Koç, "Ankara - Polatlı biyogaz enerji santrali, Sakarya mah. $102-1$ ve $117-40$ parsellere ait 1/1000 ölçekli imar plan değişikliği plan açıklama raporu", (2020)

[2] Ankara Üniversitesi, Gama Meslek Yüksekokulu, Elektrik ve Enerji Bölümü, Alternatif Enerji Kaynakları Teknolojisi, Elektrik Enerji Santralleri, 12. hafta ders notları URL: https://acikders.ankara.edu.tr/pluginfile.php/63672 /mod_resource/content/0/12.\%20HAFTA.pdf

(Erişim zamanı: Aralık, 12, 2020) [3]URL:http://deneysan.com/Content/images/d ocuments/es-07_182760.pdf (Erişim zamanı: Aralık, 12, 2020)
[4] M. Yılmaz, “Türkiye'nin Enerji Potansiyeli ve Yenilenebilir Enerji Kaynaklarının Elektrik Enerjisi Üretimi Açısından Önemi”, (Ankara Üniversitesi Çevrebilimleri Dergisi) 4(2), 33-54 (2012).

[5] H. Çelikkaya, "Biyogaz" Fırat Kalkınma Ajans1, (2016)

[6] Cemre Görmüş, “ Türkiye' deki hayvan gübrelerinin biyogaz enerji potansiyelinin belirlenmesi", Yüksek Lisans tezi, Tekirdağ Namik Kemal Üniversitesi, Fen Bilimleri Enstitüsü, Tekirdağ, 2018.

[7] Harran Üniversitesi, URL: http://web.harran.edu.tr/assets/uploads/other/files/ muhendis/files/B\%C4\%B0T\%C4\%B0RME_POS TER_en_son.pdf (Erişim zamanı: Aralık, 12, 2020)

[8] J. Gülen and H. Arslan "Biyogaz" Sigma (Mühendislik ve Fen Bilimleri Dergisi), Say1:2005/4, Ekim 2005.

[9] H. Yağlı and Y. Koç "Hayvan Gübresinden Biyogaz Üretim Potansiyelinin Belirlenmesi: Adana İli Örnek Hesaplama" (Çukurova Üniversitesi Mühendislik Mimarlık Fakültesi Dergisi) Sayı:34(3), ss.35-48, Eylül 2019

[10] Y. Noorollahi, M. Kheirrouz, H.F. Asl, H. Yousefi and A. Hajinezhad, "Biogas Production Potential from Livestock Manure in Iran,", Renewable and Sustainable Energy Reviews, vol. 50, pages 748-754, October 2015.

[11] P. Abdeshahian, J. S. Lim, W. S. Ho, H. Hashim, and C.T. Lee, "Potential of Biogas Production from Farm Animal Waste in Malaysia," Renewable and Sustainable Energy Reviews, vol. 60, pages 714-723, July 2016

[12] R. Ilgar, "Hayvan Varlığına Göre Çanakkale Biyogaz Potansiyelinin Tespitine Yönelik Bir Çalışma" Doğu Coğrafya Dergisi (Atatürk Üniversitesi Dergisi) Say1:35, s.89-106, Şubat 2016.

[13] S. Görgülü "Burdur İlinin Hayvansal ve Bazı Tarımsal Atık Kaynaklı Biyogaz Potansiyelinin Belirlenmesi “, ECJSE (El-Cezerî Fen ve Mühendislik Dergisi), Cilt: 6, No: 3, s.543-557 Haziran 2019 